Journal of Business and Tourism

Volume 04 Number 02

July-December, 2018

\title{
Assessing the Influence of Selected Human Capital Management Factors on the Organizational Performance of Higher Education Sector in Afghanistan
}

\author{
MOHAMMAD QASIM AYAZ \\ Lecturer, Management Science Department \\ Alfalah University, Afghanistan \\ Mohammadqasimayaz@gmail.com \\ ABDUL QAHAR \\ Lecturer, Management Science Department \\ Khorasan University, Afghanistan \\ abdulqahar@gmail.com \\ DR. RAZA ULLAH \\ Assistant Professor, Department of Management Sciences \\ Islamia College Peshawar \\ raza@icp.edu.pk \\ DR. MUSTAFA AFEEF \\ Assistant Professor, Department of Management Sciences \\ Islamia College Peshawar \\ mustafa@icp.edu.pk
}

\begin{abstract}
Human resources are found to be one of the most fundamental contributors in the success of any organization. In the context of the education sector, the importance to be attributed to the potential human capital and its management is ever-increasing. The main purpose of the study is to establish the influence of human capital management on performance of an organization, particularly within the education sector of Afghanistan. For this purpose, 20 universities were selected, amongst which 10 universities were private and the rest 10 were government institutions. The study used questionnaire method to collect the required data from selected public and private universities in Afghanistan. Three hundred employees were sampled from various higher education institutions of the country, both public and private and the data were analyzed through SPSS 16 version. The findings of the study depict a strong positive relationship between human capital management and organizational performance.
\end{abstract}

Keywords: Higher Education, Human Capital Management, Human Capital Theory, Organizational Performance 


\section{Introduction}

Organizational performance is one of the essential research areas that most of the researchers and practitioners have focused over time. The study at hand aims to discuss how performance of an organization can be affected by human capital management within an organization. The effect of human capital on public and private organizational performance has been studied in countries like Malaysia, Pakistan, India and Iran. Different factors have been previously linked and associated with the performance of both private and public organizations (Kulkalyuenyong, 2012). According to Majida, Samad, Tazilahc and Hanayshad (2017), the performance of an organization is one of the most important factors to be focused. Various studies have been conducted in Malaysian private and public organizations to measure the effect of human capital on performance level of selected organizations. Furthermore, public organizations have made lots of efforts in defining strategies to develop their performance. The results of the study undertaken by Majida, Samad, Tazilahc and Hanayshad (2017) showed that the human capital should be given the utmost importance in order to improve the performance of Malaysian organizations. This study endeavors to identify the key organizational performance factors in both private and public sector organizations of the higher education sector in Afghanistan.

The current study aims to measure how human capital management can bring positive effect on organizational performance in Afghanistan higher education. Additionally, this study also aims to provide an insight of organizational performance and its linkage to human capital management. The work is expected to add to the existing knowledge regarding the role of human capital on organizational performance.

\subsection{Objectives of the Study}

The current study is aimed at meeting the following main objectives:

1. To assess the impact of human capital management on organizational performance.

2. To understand the relationship between leadership practices, employees engagement, knowledge accessibility and organizational performance.

\subsection{Research Questions}

Based on the objectives of the study, the following research questions have been designed for the study:

1. What is the influence of human capital management on organizational performance?

2. How does leadership practices effect organizational performance in the education sector of Afghanistan?

3. How does knowledge accessibility support organizational performance in the higher education sector of Afghanistan?

4. To what extent the learning capacity of employees can effect the higher education sector of Afghanistan?

\subsection{Research Hypothesis}

The research questions mentioned above, therefore, translate into the following legitimate hypotheses for the study:

$H_{1}$ : Human capital management has a significant impact on organizational performance. 
$H_{2}$ : Leadership practices significantly affect organizational performance.

$\mathrm{H}_{3}$ : Knowledge accessibility significantly impacts organizational performance.

$\mathrm{H}_{4}$ : Learning capacity significantly influences organizational Performance.

\section{Literature Review}

Human capital has been theoretically and empirically linked with organizational performance (Seleim, Ashour \& Bontis, 2007). For decades, lots of comparative research studies have been carried out on human capital and organizational performance (Samad, 2012). According to Coleman (1988), human capital means the overall potential that individuals have; for instance, knowledge, attitude, work behavior, abilities. However, Schweiger, Sandberg and Ragan (1986) suggest that for every firm human capital plays model role and supports organization performance. They note that organizations specifically take care of their human capital performance better than those who don't. The remaining part of literature is divided into three sections to account separately for each of the three aspects of human capital management.

\subsection{Leadership Practices and Organizational Performance}

Several leadership approaches have been proposed by researchers including economic return and survival for instance Bass (1999). He suggests that implementing leadership practices such as transformational and transactional would be a good measure for organizational performance under certain circumstances. Bass suggests a positive relationship between transformation leadership and organizational performance. Leadership concept has been broken down into various leadership practices, as described by Kouzes and Posner (2002), which represent linkages with organizational performance. They specifically pointed out that the attributes and behaviors are particularly effective for leaders in achieving superior organizational performance.

\subsection{Knowledge Accessibilities and Organizational Performance}

Utilization, sharing, and ownership appear as three main approaches between knowledge management and organizational performance (Cater \& Cater, 2009). Utilization connotes the effectiveness of utilizing the existing knowledge in an organization for better advancement. Sharing means the improvement of sharing formal and informal knowledges which affect organizational performance. Ownership means the better the accessibility of knowledge the greater organizational success and affective performance. Multi-dimensional construct in organizations behavior offers a holistic picture of multifarious occurrences (Hanisch, Hulin, \& Roznowski, 1998; Roznowski \& Hanisch, 1990). Hence a learning environment needs conversion of tacit and explicit knowledge facilitate effective knowledge management and demands congruent support at all level within an organization. For knowledge accessibility, other than technology interventions; organization and work design, and organizational culture play a important role to induce learning at workplace (Li et al., 2009).

\subsection{Learning Capacity and Organizational Performance}

It can be easily understood that learning capacity is a key feature for organizational development in both economic and as well as organizational terms, and at the moment organizations are facing high level innovative technology which provide tough competitive environment (Siguaw, 2000). The current literature explores a great contribution of learning capacity in almost every field of the study (Argot, 2012; Huber, 1991; Popper and Lipshitz, 2002; Sinkula, 1995). Different studies suggest significant 
relationship between learning capacity and organizational performance and effectiveness (Hagedoorn and Cloodt, 2003; Nonaka and Takeuchi, 1996; Rose, 2011; Sun and Scott, 2003).

\section{Research Methodology}

The current study used a quantitative approach to conceptualize the problem. Based on literature review, the main components namely leadership practices, knowledge accessibility and learning accessibility, and organizational performance were selected. The human capital management serves as the independent variable whereas organizational performance is the explained variable of the study. A total of 20 universities was selected among which 10 were from public sector and the remaining 10 from private sector. A total of 360 questionnaires were distributed which yielded in $50 \%$ response rate which is quite normal in Asian context (Tufail, Shahzad, Gul \& Khan, 2017). The sample size for this study was 300 respondents who participated in filling the questionnaires and sharing their valuable ideas and opinions. The data was collected through convenient sampling technique from selected public and private higher educational institutions. Regression analysis was performed to establish a relationship between the dependent and the explanatory variable used in the study using SPSS package.

\section{Results and Findings}

This section provides the analysis portion of the document. The section starts with the demographic details of the respondents and then moves on to give the correlation coefficient between the two variables. It then runs the regression analysis between our variables of interest in order to trace any significant relationship between the two.

Table 1: Demographics of the Respondents

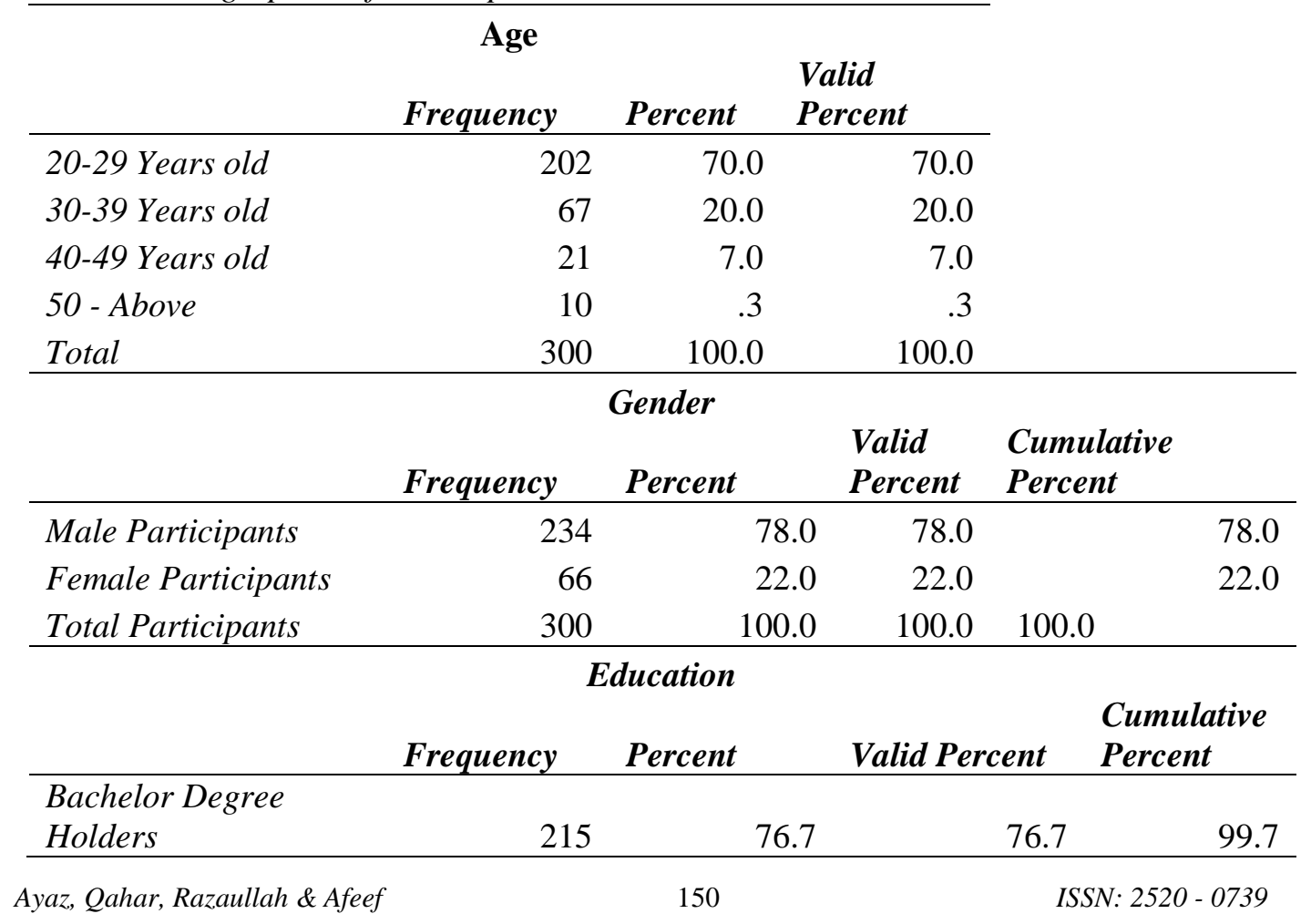




\begin{tabular}{|c|c|c|c|c|}
\hline \multicolumn{5}{|l|}{ Master Degree } \\
\hline Holders & 60 & 14.5 & 14.5 & 0.3 \\
\hline \multicolumn{5}{|l|}{ M.Phil Degree } \\
\hline Holders & 23 & 7.9 & 7.9 & 100 \\
\hline PhD Degree Holders & 2 & 0.9 & 0.9 & \\
\hline Total & 300 & 100.0 & 100.0 & \\
\hline \multicolumn{5}{|c|}{ Experience } \\
\hline & Frequency & Percent & Valid Percent & $\begin{array}{l}\text { Cumulative } \\
\text { Percent }\end{array}$ \\
\hline $\begin{array}{l}5-10 \text { Years Experience } \\
11-15 \text { Years }\end{array}$ & 177 & 59.0 & 59.0 & 59.0 \\
\hline $\begin{array}{l}\text { Experience } \\
16-20 \text { Years }\end{array}$ & 89 & 29.7 & 29.7 & 88.7 \\
\hline Experience & 33 & 11 & 11.0 & 99.7 \\
\hline 21 or above & 1 & 0.3 & 0.3 & 100.0 \\
\hline Total & 300 & 100.0 & 100.0 & \\
\hline
\end{tabular}

For this study the total number of the participants was 300 and the researchers tried to let them discuss their age, gender, education level and experience. The results from demographic section explores that most of the participants were between 20-29 years of age and were 202 in number. The number of male participants in the study was 234 which is equal to $78 \%$ of the sample whereas the number of female participants was 66 which makes up only $22 \%$. This shows that the higher education institutions at Afghanistan are highly male dominated with a little representation of females.

The educational level in the demographic section is noticeable. The number of participants who only completed their bachelor degree in different disciplines is 215 , master degree holders participation in the study was 60, the number of M. Phil degree holder who participated was 23 , and only one $\mathrm{PhD}$ degree holder was there in our sample. As far as the experience level of the respondents in different work places is concerned, $59.7 \%$ percent of the participants had between 5-10 years of experience, while $29.7 \%$ percent of the participants recorded their experience level was between 11-15 years. The remaining $11 \%$ of sampled respondents had between 16-20 years of experience.

Table 2: Pearson Product Moment Correlation

\begin{tabular}{llrr}
\hline & & $\begin{array}{c}\text { Human Capital } \\
\text { Management }\end{array}$ & $\begin{array}{c}\text { Organizational } \\
\text { Performance }\end{array}$ \\
\hline & Pearson Correlation & 1 & \\
Human Capital Management & Sig. (2-tailed) & & \\
& $\mathrm{N}$ & 300 & 1 \\
& Pearson Correlation & .343 & \\
Organizational Performance & Sig. (2-tailed) & $(.047)$ & 300 \\
& $\mathrm{~N}$ & 300 & \\
\hline
\end{tabular}


The correlations table gives the positive relationship between human capital management and organizational performance with a correlation coefficient of .343 at 5\% significance level.

Table 3: Model Summary

\begin{tabular}{cccc}
\hline $\mathrm{R}$ & R Square & Adjusted R Square & $\begin{array}{c}\text { Std. Error of the } \\
\text { Estimate }\end{array}$ \\
\hline .178 & .132 & .121 & 2.114 \\
\hline
\end{tabular}

The model summary presents the R square and the adjusted $\mathrm{R}$ square values of the model in which the human capital serves as the explanatory variable and the performance represents the dependent variable. As can be noted, the adjusted $\mathrm{R}$ square value of the model is .121 which tells that around $12.1 \%$ of the variability in the dependent variable is explained by the human capital management. Since not much explanatory variables are included in the study, an adjusted $\mathrm{R}$ square value of .121 is not bad enough.

Table 4: ANOVA

\begin{tabular}{lccccc}
\hline & Sum of & Df & Mean Square & F & Sig. \\
& Squares & & & & \\
\hline Regression & 42.890 & 4 & 10.723 & 12.869 & .009 \\
Residual & 1318.346 & 295 & 4.469 & & \\
Total & 1361.237 & 299 & & & \\
\hline
\end{tabular}

a. Dependent Variable: Organizational Performance

b. Predictors: (Constant), Learning Capacity, Human Capital Management, Knowledge Accessibility, Leadership Practices

The ANOVA table presented above gives $\mathrm{F}$ statistic value which represents the significance of the model overall. The value of the F statistic is 12.869 which is significant as well ( $p$ value $=.009)$. This depicts that the model is a good fit overall.

Table 5: Regression Results

\begin{tabular}{cccccc}
\hline & \multicolumn{2}{c}{$\begin{array}{c}\text { Unstandardized } \\
\text { Coefficients }\end{array}$} & $\begin{array}{c}\text { Standardized } \\
\text { Coefficients }\end{array}$ & T & Sig. \\
& $\mathrm{B}$ & Std. Error & Beta & & \\
& 21.36 & .687 & & 31.121 & .000 \\
(Constant) & 7 & & & & \\
Human Capital Management & .190 & .034 & .033 & 5.59 & .013 \\
\hline
\end{tabular}

a. Dependent Variable: Organizational Performance

The regression results give the coefficient of the explanatory variable. The unstandardized beta coefficient for human capital management is .190 with a standard error of .034. This translates into a $t$-statistic of 5.59 which makes the association statistically significant at $5 \%$ level. Thus, we can say that human capital management is associated with a .190 increase in organizational performance such that a one unit increase in the human capital management leads to a 19 percent increase in the performance. 


\section{Conclusion}

The primary objective of the study was to assess the influence of human capital management, leadership practices, knowledge accessibility and learning capacity on organizational performance of the higher education sector in Afghanistan. The findings of this research study contributes by having huge implications in both business and academic arena in line with the findings of (Afiouni 2013; Santos-Rodrigues, Delery and Roumpi 2017; Dorrego, and Jardon, 2010). It revealed that there is a positive significant relationship between human capital management and the organizational performance. The results of the study suggest that a better management of human capital will accelerate organizational performance. An increase in the learning capacity of employees will increase their ability to utilize their knowledge and influence organizational performance. The study suggests a need to develop an organizational culture that focuses on motivating and encouraging employees to enhance their abilities, skills and competency which would, in turn, have a positive influence on organizational performance and increase its effectiveness.

\section{References}

Afiouni, F. (2013). Human Capital Management: A New Name to HRM, Int. J. Learning and Intellectual Capital, Vol. 10, No. 1.

Argote, L. (2012). Organizational learning: Creating, retaining and transferring knowledge. Springer Science \& Business Media.

Bass, B. (1999). Two decades of research and development in transformational leadership. European journal of work and organizational psychology, 8(1), 9-32.

Cater, B., \& Cater, T. (2009). Relationship-value-based antecedents of customer satisfaction and loyalty in manufacturing. Journal of Business \& Industrial Marketing, 24(8), 585-597.

Coleman, J. (1988). Social capital in the creation of human capital. American journal of sociology, 94, 95-120.

Delery, J., and Roumpi, D. (2017). Strategic human resource management, human capital and competitive advantage is the field going in circles? Human Resource Management Journal, 27 (1).

Hagedoorn, J., \& Cloodt, M. (2003). Measuring innovative performance: is there an advantage in using multiple indicators?. Research policy, 32(8), 1365-1379.

Hanisch, K. A., Hulin, C. L., \& Roznowski, M. (1998). The importance of individuals' repertoires of behaviors: The scientific appropriateness of studying multiple behaviors and general attitudes. Journal of Organizational Behavior, 19, 463-480.

Huber, G. P. (1991). Organizational learning: The contributing processes and the literatures. Organization science, 2(1), 88-115.

Kouzes, J., \& Posner, B. (2002). The leadership practices inventory: Theory and evidence behind the five practices of exemplary leaders. Unpublished document. Retrieved February, 12, 2010.

Kulkalyuenyong, P. (2012). Analysis of organizational culture and commitment to the Ministry of Public Health under the central administration: A comparative study 
of service agents and policy agents. School of Public Administration, Chulalongkorn University, Thailand: PhD Thesis.

Li, J, Brake, G., Champion, A., Fuller, T., Gabel, S., \& Hatcher-Busch, L. (2009)

"Workplace learning: the roles of knowledge accessibility and management", Journal of Workplace Learning, Vol. 21 Issue: 4, pp.347-364

Majida, M., Samad, S., Tazilahc, M., \& Hanayshad, J. (2017). Human capital and organizational performance of Malaysian government agencies: A conceptual paper. Nonaka, I., \& Takeuchi, H. (1996). The knowledge-creating company: How Japanese companies create the dynamics of innovation. Long range planning, 4(29), 592.

Popper, M., \& Lipshitz, R. (2000). Organizational learning: Mechanisms, culture, and feasibility. Management learning, 31(2), 181-196.

Rose, H. (2011). Re-conceptualizing strategic learning in the face of self-regulation: Throwing language learning strategies out with the bathwater. Applied Linguistics, 33(1), 92-98.

Roznowski, M., \& Hanisch, K. A. (1990). Building systematic heterogeneity into work attitudes and behavior measures. Journal of Vocational Behavior, 36, 361-375. Samad, S. (2012). The influence of innovation and transformational leadership on organizational performance. Procedia-Social and Behavioral Sciences, 57, 486-493. Santos-Rodrigues, H., Dorrego, P.F. and Jardon, C.F. (2010) 'The influence of human capital on the innovativeness of firms', International Business and Economics Research Journal, Vol. 9, No. 9, pp.53-63.

Schweiger, D., Sandberg, W., \& Ragan, J. (1986). Group approaches for improving strategic decision making: A comparative analysis of dialectical inquiry, devil's advocacy, and consensus. Academy of management Journal, 29(1), 51-71.

Seleim, A., Ashour, A., \& Bontis, N. (2007). Human capital and organizational performance: A study of Egyptian software companies. Management Decision, 45(4), 789-801.

Siguaw, J., Enz, C., \& Namasivayam, K. (2000). Adoption of information technology in US hotels: Strategically driven objectives. Journal of Travel Research, 39(2), 192201.

Sinkula, J. M. (1994). Market information processing and organizational learning. the Journal of Marketing, 35-45.

Sun, P. Y., \& Scott, J. L. (2003). Exploring the divide-organizational learning and learning organization. The learning organization, 10(4), 202-215.

Tufail, M., Shahzad, K., Gul, A., \& Khan, K. (2017). The Impact of Challenge and Hindrance Stressors on Job Satisfaction: Moderating Role of Islamic Work Ethics. Journal of Islamic Business and management, 7(1), 100-113. 